\author{
BULETINUL INSTITUTULUI POLITEHNIC DIN IAŞI \\ Publicat de \\ Universitatea Tehnică „Gheorghe Asachi” din Iaşi \\ Volumul 67 (71), Numărul 2, 2021 \\ Secţia \\ CONSTRUCȚII DE MAȘINI \\ DOI:10.2478/bipcm-2021-0009 \\ sciendo
}

\title{
ASPECTS CONCERNING THE USE OF MAGNETOREOLOGICAL FLUIDS IN CONSTRUCTION OF SHOCK ABSORBERS
}

BY

\section{CORNELIU-DANIEL GHIORGHE* and DORU CĂLĂRAŞU}

"Gheorghe Asachi" Technical University of Iaşi,

Faculty of Mechanical Engineering, Iaşi, Romania

Received: March 29, 2021

Accepted for publication: May 28, 2021

Abstract. In this paper, a review is made of the knowledge about magnetorheological fluids which are part of the class of intelligent materials. These are the fluids that do not comply with Newton's law, their energization being realized through an external magnetic field. Essentially, magnetorheological fluid is a synthetic solution based on hydrocarbons, populated with soft magnetic particles (easy to magnetize and demagnetize). Shock absorbers that use magnetic fluids are found in the automotive industry for vibration pick-up. The shock absorber with elastic element and magnetorheological fluid presents the following advantages: the possibility of electric control of the stroke and the speed of response of the piston-cylinder system, by a contactless method; it has a simple and reliable construction; the proposed shock absorber is a watertight construction; no internal sealing elements compatible with the magnetorheological fluid are required; the shock absorber does not have components with relative movement at the level of the control element, reducing frictional forces.

Keywords: intelligent fluids; magnetorheological shock absorbers; elastic element shock absorbers; piston-cylinder shock absorbers; non-Newtonian fluids.

*Corresponding author; e-mail: cornelghiorghe28@gmail.com

(C) 2021 Corneliu Daniel Ghiorghe et al.

This is an open access article licensed under the Creative Commons Attribution-NonCommercialNoDerivatives 4.0 International License (CC BY-NC-ND 4.0). 


\section{Introduction}

Intelligent materials include electro-rheological materials, magnetorheological (MR) materials, shape memory alloys, piezoelectric materials and electroactive polymers. Of all the magneto-rheological materials, magnetorheological fluids are the most widely used due to their rapid response, dramatic change rheology, insensitive to contamination and an easy preparation procedure (Hajalilou et al., 2016; Jolly et al., 1998; Melle et al., 2000; Olabi and Grunwald, 2007; Tang et al., 2000). Magnetorheological fluids are in the form of a micronized suspension, magnetizable particles in a carrier fluid, being the most commonly encountered magneto-rheological materials.

In recent years these materials have been used successfully in the automotive industry to improve the shock absorbers.

It is known that the suspension is a set of elements interposed between the machine and the foundation with the role of reducing the amplitude of the movement transmitted from the machine to the foundation and vice versa. The car's suspension system has the role of absorbing the irregularities of the treadmill, keeping the wheels in constant contact with the treadmill and providing good comfort to the passengers. The suspension of the car makes the elastic connection between the frame, body and axles or directly with the wheels of the car. When vehicles move on roads with uneven surfaces, the speed is usually not limited by the power of the engine, but by the quality of the suspension.

It has been found that the use of magnetorheological fluids in shock absorbers improves their performance. The dampers are filled with a magnetorheological fluid, which, after applying an external magnetic field, passes from the liquid state to the semi-solid state, which allows the field to control the damping characteristics.

With relatively recent applications, the magnetorheological shock absorber has the advantages of the reaction speed and the accuracy of the damping. The first suspension with magnetorheological shock absorbers installed on a series model appeared in 2002 on Cadillac cars (Shutto and Toscano, 2005; Carlson and Jolly, 2000). Today, the list of vehicles using magnetorheological shock absorbers is long and includes big names, such as Ferrari, Porsche, Land Rover, Range Rover, Audi (Spaggiari, 2013; Genc, 2002; Goncalves, 2005).

On the outside, the magnetorheological shock absorber looks like an ordinary monotube, but two special things are noted: the lack of valves that control fluid leakage and the absence of moving components. This is possible precisely because of the properties of the magnetorheological fluid that belongs to the category of intelligent fluids, namely the magnetic controllable fluids.

Magnetorheological fluids are rheological fluids that do not comply with Newton's law, being characterized by their energizing by means of an external magnetic field. 
Essentially, magnetorheological fluid is a synthetic solution based on hydrocarbons, populated with soft magnetic particles (easy to magnetize and demagnetize).

There are known a series of shock absorbers that use magnetic fluids, found in the automotive industry (vibration shock absorbers), in the structure of earthquake protection systems, in the composition of limb protection systems.

\section{General Data on Magnetorheological Fluids}

Fluids can be of two types: non-Newtonian and Newtonian.

The Newtonian fluid is that fluid that has, in laminar flow, stationary isotherm, a proportionality between the tangential voltage and the deformation velocity (velocity gradient). For example, a simple substance, such as water, is in a solid state with the hard, crystalline and three-dimensional structure if it is below the freezing point. Also, the same fluid is a Newtonian liquid, of low viscosity, if it is at a temperature above the freezing point. In the liquid state, the mechanical properties of such a substance are appreciated by its shear viscosity, $\eta$, which is dependent on temperature and pressure. In the world there are a number of complex fluids, resulting from the condensed phase, which are neither liquid nor simple crystalline solids, from the point of view of the classical definition (Truong and Ahn, 2012).

Newtonian fluids do not comply with Newton's law.

These are complex fluids that have intermediate mechanical properties between those of classical solids and liquids, properties that cannot be described by the values of modulus of elasticity and viscosity. The essential difference between solids and conventional liquids is the ability of liquids to take the shape of the container in which they are placed (Dewi et al., 2018). Classical crystalline solids are anisotropic (their properties depend on the orientation of the deformation applied to the crystallographic axes) (Tian et al., 2011).

Classical liquids are isotropic. Liquid crystals flow like liquids, but they are anisotropic. In contrast, complex fluids are capable under certain conditions to maintain their shape, and in other conditions may flow. Because they can be considered "solid" for short periods of time and "liquid" for longer periods, complex fluids have been called viscoelastic. Depending on the type of complex fluid, the transition from "solid" to "liquid" state can vary from fractions of seconds to days or even years. Other types of complex fluids can evolve from solid type to liquid type or vice versa, when they are subjected to modest deformations (polymeric or particle gels) or can be transformed into solids when placed in electric or magnetic field (electrorheological and magnetorheological suspensions). In contrast, classical liquids do not change their character unless they are brought to a temperature very close to the phase transformation (Skalski and Kalita, 2017). 
Other complex fluids represent intermediate states between liquids and solids, from several points of view: liquids;

- liquid crystalline polymers (LCP) are both crystalline and viscoelastic

- ordered block polymers are viscoelastic and anisotropic;

- in vitro polymers have high viscoelasticity due to their polymeric and amorphous nature;

- saturated polymer melts (filled polymeric melts) have properties of suspensions and polymeric melts (Tian et al., 2011).

The main similarities and differences between the rheological (flow) properties of different complex fluids are:

- the linear viscosity, determined by means of the storage (storage), G 'and loss modules, $\mathrm{G}$ "(which reflects the properties of the material at rest);

- flow curve, which expresses the relationship between shear viscosity, $\eta$ and shear rate, (which shows how the material changes when subjected to continuous deformation) (Tian et al., 2011).

A material is solid or liquid depending on its rheological properties. Due to the fact that these properties depend on the time interval in which the determination is made, a rheometer measures the rheological properties of a complex fluid depending on the speed or frequency of deformation. In the case of liquids, the simplest rheological devices involve:

- applying a shear flow and measuring the resulting stresses;

- applying a shear stress and measuring the resulting shear rate (Raju et al., 2018).

The main methods of quantitative characterization of complex fluids are flow, sliding on the wall and apparent flow. To these are added qualitative methods, such as: microscopy, radiation diffraction and polarimetry.

The viscous flow of the simple liquids is expressed by the viscosity $\eta 0$. In the absence of macroscopic flow, the molecules pulsate individually due to Brownian motion. Under the effect of an applied voltage, the pulse speed in the same direction as the voltage becomes higher than in the opposite direction and a displacement in time occurs. At high flow rates hydrodynamic instabilities of the simple fluids that lead to secondary flows due to inertial or elastic effects may occur.

In the flow of simple fluids there are solid boundaries, represented by the marginal surfaces, against which the fluid must flow, without adhering. This sliding of the fluid is evident when it is made between two plates, one being in motion.

A complex fluid can behave as a liquid at low shear speeds or as a solid at high speeds. For this reason, when they have a solid type behavior, complex fluids can slide against solid walls. Solid-type behavior occurs when the storage module, $G^{\prime}$ is much larger than the loss module, $G^{\prime \prime}$. An example of a sliding wall can provide an aqueous foam that is sheared between two smooth surfaces. 
Foam water can form a lubricating layer on the wall, which causes the main mass of foam to be sheared to a lesser extent.

Apparent flow or plastic deformation is characteristic of viscous liquids. It is triggered after the flow voltage is exceeded, which depends on the deformation speed and the temperature. Typical examples of complex fluids that support the apparent flow phenomenon are glass polymers.

Microscopy is one of the most direct ways to obtain information about the structure of complex fluids.

Optical microscopy can analyze images with a resolution of $0.5 \mu \mathrm{m}$. At this level can be analyzed structures and textures supermolecular, generating voltage, which are present in emulsions, mixtures, liquid crystals and suspensions of large particles. For analyzing the flow or deformation, flow cells are mounted on the optical microscopes. Some biological macromolecules (e.g. DNA) can be observed directly in fluorescence microscopes. Optical microscopy can be combined with micromanipulation to measure the mechanical properties of complex fluids.

Magnetorheology is the branch of rheology that deals with the flow and deformation under the effect of an applied magnetic field. The discovery of magnetorheological fluids is attributed to Jacob Rabinow, in 1949. Magnetorheological fluids are suspensions of soft, magnetically, multidomain, non-colloidal $(0.05-10 \mu \mathrm{m})$, in organic or aqueous liquids. Several ceramic metals and alloys that can be used for the preparation of magnetorheological fluids have been described, as long as the particles are multi-domain, magnetically, and exhibit low levels of magnetic coercivity. The most important characteristics of the dispersed phase, which are magnetically active, are particle size, shape, density, distribution, magnetic saturation and coercive field. Other important factors that affect the rheological properties, stability and redispersibility of magnetorheological fluid are surfactants and anticorrosive additives (Olabi and Grunwald, 2007).

Electron microscopy can reach resolutions of: $15 \AA$ at scanning, SEM; $0.5 \AA$ at transmission, TEM. Due to the vacuum conditions, electron microscopy cannot be used to study the flow of complex fluids. SEM was used for the in-situ study of the deformation and rupture of polymers, using displacement markers, traced with the electron or ion beam provided by the microscope.

Light, X-ray and neutron scattering offer one of the most efficient methods of studying complex fluids. X-ray scattering or neutron scattering are useful for studying molecular structures.

Many of the complex fluids contain microstructures, particles and orientable molecules that rotate during or under the influence of electric or magnetic fields. If these molecules have anisotropic polarizabilities, then their refractive index will be orientation dependent. In this case the respective material is birefringent. 
Materials whose rheological properties can be modified by applying magnetic fields belong to a specific class of so-called intelligent materials, because they can respond, through solid state electronics and modern control algorithms, to changes in their environment.

In a scientific paper, MR Jolly focused on materials consisting of a suspension of non-colloidal particles, magnetically polarizable in a nonmagnetic environment (Jolly, 1999). These materials respond to the applied magnetic fields and are thus called magnetorheological materials. Such materials can be used in devices or incorporated into traditional composites to form advanced intelligent composite structures whose continuous magnetorheological response can be actively controlled in real time. There are numerous applications that can benefit from materials whose rheology can be varied continuously, quickly and reversibly.

Magnetorheological fluids have a composition similar to that of ferrofluids, being characterized by multiple magnetizable particles in a non-magnetic environment. Because they have different particle sizes and compositions, they have a special behavior. Magnetorheological fluids with larger particles are more stable and highly magnetizable and allow their reversible conglomeration. The movement of the poles in the field causes attraction between particles. The highest value of the particle attraction is achieved when the saturation of the magnetic particles is maximum. As it is known, iron has among the best magnetic properties with $\mathrm{J}=2.1$ Tesla.

Following the chemical process of decomposition of iron pentacarbonyl, iron particles are globular, with volumes between 0.1-0.5. In research by Carlson J.D. et al., it was observed that the magnetization of iron and cobalt alloys has a higher value $(\mathrm{J}=2.4$ Tesla) which led to their use for the production of magnetorheological fluids (Carlson et al., 1995).

BASF researchers have created magnetorheological fluids based on $30 \mathrm{~nm}$ diameter ferrite particles coated with long chain molecules (Kormann et al., 1994). It has been observed that these fluids are very stable and resistant to abrasion, but have a lower flow resistance than fluids containing iron particles, due to the lower magnetic properties of the ferrite.

Among the complex liquid fluids that have good rheological and tribological properties, as well as good temperature stability, we can mention the following: petroleum oils, silicone, mineral oils, polyesters, polyether, water, synthetic hydrocarbon oils.

Some researchers have observed that by using fluids containing specific additives, lubrication has been improved and sedimentation and agglomeration have been inhibited (Ashour et al., 1996; Kormann et al., 1994).

Sedimentation is usually controlled by the use of agents with special characteristics (Shtarkman, 1991; Winslow, 1949). These agents improve the properties of magnetorheological fluids (Shtarkman, 1991; 1992). The fibers 
create viscosity through a physical network, but they present a thinning due to the shear-induced alignment.

The most common magnetorheological materials are liquid. The controllable rheological response of these fluids results from the polarization induced in the suspended particles by applying an external magnetic field. The interaction between dipoles induces results that cause the formation of particles of columnar structures, parallel to the applied field. These chain-shaped structures limit the fluid flow, thus increasing the viscous characteristics of the suspension. The mechanical energy required to generate these chain-like structures increases as the applied magnetic field increases, resulting in a fielddependent request. In the absence of an applied field, controllable fluids exhibit Newtonian-like behavior. The discovery and initial development of magnetorheological fluids and devices can be credited to Jacob Rabinow at the United States National Bureau of Standards (Rabinow, 1948). Interestingly, this work was almost concurrent with Willis Winslow's work on electrorheological fluids (Winslow, 1949). With the exception of a flame of interest after their initial discovery, little information about magnetorheological fluids has been published. Only recently has there been a renewed interest in the observed magnetorheological fluids (Shtarkman, 1991; 1992).

Thus, Stănescu and colleagues invented a lubricating composition, used as hydraulic fluid, for telescopic shock absorbers and hydraulic systems with high mechanical demands. The lubricating composition, according to the invention, consists of: $86-98.8 \%$ mineral base oil, obtained from selected oil fractions (Stănescu et al., 2001).

Vidican et al., in a paper submitted in 2013, say that the shock absorbers used in the suspension of railway vehicles have the role of rapidly dissipating the energy of the vertical oscillations of the body and the wheels of the vehicle by converting it into caloric energy transferred to the environment (Vidican et al., 2013). They are mounted in parallel with the main elastic elements of the suspension and are a basic element in ensuring the comfort and safety of the movement.

In the most used railway vehicles, the shock absorbers are the telescopic hydraulic shock absorbers. The working principle of these shock absorbers consists of the following: at the relative displacement of the suspended mass relative to the unsuspected mass, the viscous liquid from the body of the shock absorber is forced to pass through the small section holes.

Magnetorheological shock absorbers are built like hydraulic shock absorbers, with the difference that magnetic fluid is introduced into the working cylinder. Magnetic liquids - ferrofluids, have very common properties of liquids, but they also behave as a highly magnetizable material. The number of these magnetic particles is very large, with a reference value being 1023 particles per cubic meter. The first magnetic liquids were prepared in 1960 by NASA, as part of space technology research, to develop a controlled flow 
system of fuels under imponderable conditions. Magnetic liquids (ferrofluids) are dispersions of magnetic particles in a basic liquid.

Each colloidal particle in a magnetic fluid is a small permanent magnet that tends to align in the direction of the magnetic field. The particle size being very small $(\sim 10 \mathrm{~nm})$, the thermal agitation prevents their sedimentation. In addition, the particles are coated to prevent their magnetic interaction. This results in a complex mixture that acts as a homogeneous liquid even in the presence of an externally applied magnetic field.

Initially made of hydrocarbons as a base liquid, magnetic liquids are produced in different liquids, having physical and chemical properties that vary in a very wide range.

Commercial ferrofluids are produced in water, silicone, fluorocarbons, esters and other solvents. They have a wide range of viscosity, humidity, density, miscibility, surface tension and other properties. By controlling the numerical density of the suspended magnetic particles, they can vary the saturation magnetization and the relative magnetic permeability of the magnetic liquids.

Having the basic component of magnetic liquids, magnetic nanoparticles, they fall into a broad category of intelligent nanoparticles, respectively in the leading field of nanoscience, nanotechnologies.

\section{Areas of Use of Magnetorheological Fluids. Aspects Regarding the Use of Magnetorheological Fluids in the Construction of Shock Absorbers}

Of the magnetorheological devices, the magnetorheological shock absorbers have been the most studied and developed in terms of the spread of commercial applications because they include automotive applications (Delphi Corporation producing magnetorheological shock absorbers for certain Cadilac 2003 models) (Shutto and Toscano, 2005; Lord Corporation, 2003). Magnetorheological liquids (MRs) are stable suspensions of ultrafine ferromagnetic particles with dimensions of the order of $0.05-10 \mu \mathrm{m}$ in a carrier fluid, insulating medium. When applying a magnetic field, magnetorheological materials have the ability to change their viscosity up to six orders of magnitude, due to the formation of aligned chains of particles.

Other applications for magnetorheological shock absorbers include: building control systems, earthquake attenuation, and shock absorbers and driving dynamic impact for weapons. The double tube magnetorheological damper in which the damper has an inner chamber and an outer chamber are separated from each other by a suction valve. The inner chamber guides the piston rod assembly, as well as the monotubular shock absorber. The volume 
between the inner tube and the outer tube is defined as the outer reservoir (Wang and Meng, 2001).

The magnetorheological fluid-based shock absorber has a large capacity of controllable damping force and is widely used in civil or bridge constructions (Hahm et al., 2013; Zapateiro et al., 2009). To reduce the earthquake response of the building or the wind controllable shock absorbers are widely used (Fujitani et al., 2003).

Also, magnetorheological fluids have been used in the suspension of vehicles such as tractors or dumpers, thus being able to control the vibrations and ensure comfort and safety of the driver (Jim Toscano, 2009a; Sun et al., 2016). Subsequently, their use has also been extended to the helicopter pilot's seat or the patient's bed in the ambulance (Hiemenz et al., 2008; Chae and Choi, 2014).

The largest use of these materials is found in the automotive industry, when to obtain comfort for passengers and driver, devices based on magnetorheological fluids are used in the modern vehicle suspension system, such as for heavy trucks, cars, tractors, railways and vehicle construction (Ahmadian et al., 2005; Dutta and Choi, 2016; Kim et al. 2016; Yang et al., 2016). Magnetorheological fluid is generally used to design shock absorbers that have the capacity to produce a controllable damping force. Carrera has introduced a main controllable suspension based on magnetorheological fluid for NASCAR race cars (Inha University, n.d.). Moreover, Delphi Corporation developed the suspension using Lord Corporation's MRF technology which is known as Delphi MagneRide (Shutto and Tuscano, 2005). The advantages of MagneRide are that it has no moving parts, its reliability is high and its durability is greater than $100 \mathrm{k}$ miles. Some manufacturers, such as Audi and Ferrari, have developed various MagneRide models to use in their own vehicles. Moreover, many car companies have tried to develop a clutch system based on MRF, four-wheel drive. Thus, in 2010, Porsche also introduced the Porsche GT2 and GT3, and in 2007 Honda used it on the Acura model (Yu et al., 2009; Avraam, 2009).

Wang Daoming and co-workers invented a car pedal brake simulator based on a magnetorheological shock absorber. The simulator comprises a pedal transmission mechanism, a gear transmission mechanism and a magnetorheological damping mechanism, wherein the pedal transmission mechanism, the gear transmission mechanism and the magnetorheological shock absorber mechanism are arranged separately on a base. The pedal transmission mechanism comprises a first transmission shaft, the gear transmission mechanism comprises a second transmitted shaft, connected to the first transmission shaft and a third transmitted shaft connected to the second shaft transmitted, and the magnetorheological damping mechanism, comprises a brake disc connected to the third transmission shaft. A rotary encoder is disposed at one end of the first transmission shaft, on the first transmission shaft 
a brake pedal is placed, a pedal force sensor disposed on the brake pedal, the brake disc is arranged in a closed cavity in a damper cover body and the cavity is filled with magnetorheological fluid (Wang D. et al., 2019).

Liu Yabin and colleagues invented a magnetorheological shock absorber and a magnetorheological fluid infusion method. The magnetorheological shock absorber includes a rotor, which is connected to a shaft transmitted by a key. According to the magnetorheological shock absorber and the magnetorheological fluid infusion method, the magnetorheological shock absorber is provided with at least three perfusion holes in a suitable position (Yabin et al., 2018).

Naserimojarad Mohammad Mehdi and his collaborators invented a shock absorber for a magnetorheological fluid that includes a buffer body that defines a cavity with a liquid intelligent (Naserimojarad et al., 2019; https://patents.google.com/).

On the other hand, the invention of Tian $\mathrm{Li}$ and co-workers has a magnetorheological fluid-type self-adaptive rotary dampener. The magnetorheological fluid block with self-adapting rotational type comprises a cylinder and is characterized in that the cylinder is divided into vibration excitation layers and magnetorheological damping layers, inside the cylinder is an elongated fixed shaft and a rotating shaft arranged in outside the fixed shaft and can rotate freely around the fixed shaft; each vibration excitation layer is provided with two ground blocks that can move in one direction; one end of each grounding block is connected to the inner wall of the cylinder through a spring and the other end of each grounding block is connected by a limiting bearing inside a rotating disc through a connecting rod; each magnetorheological damping layer is provided with a built-in magnetorheological fluid storage cavity and two excitation coils are disposed on each upper and lower surface of the magnetorheological fluid storage cavity; the excitation coils are connected in a circuit control chamber on the periphery of the magnetorheological fluid storage cavity; the blades are arranged inside the magnetorheological fluid storage cavities and connected to the rotary shaft (Tian, 2018; https://en.espacenet.com/).

\section{Conclusion}

Due to the very wide areas in which they can find their applicability (car dampers, machine tool supports, anti-seismic protection, etc.) magnetorheological fluids represent an extremely advantageous solution for quickly adjusting the rigidity and vibration absorption capacity, by simply modifying an electromagnetic field.

Due to specific features, such as fast response time and high power generation with low energy consumption, these materials can be considered intelligent. 
This technology has some limitations due to the resistance against the operating temperature, the wear and abrasion due to the iron particles, the sealing problems and the increased weight given by the high density of the iron particles. Another observation would be that the magnetic particles, by their oxidation, may have porous layers that influence their characteristics. However, through new research, such as the inclusion of anti-corrosive and antisedimentation substances, these disadvantages have been reduced or eliminated.

The development of these materials can be an opportunity for different fields such as mechanical engineering, civil engineering, medical, robotics, automotive, aerospace.

\section{REFERENCES}

Ahmadian M., Song X., Sandu C., Designing an Adaptive Semiactive MagnetoRheological Seat Suspension for Heavy Truck Applications, In: Proceedings of SPIE-International Society for Optics Engineering: Smart Structures and Materials 2005: Damping and Isolation, San Diego, CA, 7-10 March, 247-256.

Ashour O., Rogers CA., Kordonsky W., Magnetorheological Fluid: Materials, Characterization and Devices, J. Intell. Mater. Sys. And Struct., 7, 123 (1996).

Avraam M., MR-Fluid Brake Design and its Application to a Portable Muscular Rehabilitation Device, DoktoraTezi, 2009, Faculte' De Sciences Applique'es, Universite' Libre De Bruxelles, Bruxelles.

Carlson J.D., Weiss K.D., Magnetorheological Materials Based on Alloy Particles, US Patent 5, 382, 373-1995.

Carlson J.D., Jolly M.R., MR Fluid, Foam and Elastomer Devices, Mechatronics, 2000, 10, 555-569.

Chae H.D., Choi S.-B., A New Vibration Isolation Bed Stage with Magnetorheological Dampers for Ambulance Vehicles, Smart Materials and Structures, 24, 017001 (2014).

Dewi U.U., Saiful A.M., Fitrian I., Nur A.N., Irfan B., Siti A.A.A., Norzilawati M., Seung-Bok C., Material Characterization of a Magnetorheological Fluid Subjected to Long-Term Operation in Damper, Materials, 11, 2195, 2-17 (2018).

Dutta S., Choi S.-B., A Nonlinear Kinematic and Dynamic Modeling of Macpherson Suspension Systems with a Magneto-Rheological Damper, Smart Materials and Structures, 2016, 25, 035003.

Fujitani H., Sodeyama H., Tomura T., Hiwatashi T., Shiozakt Y., Hata K., Sunakoda K., Morishita S., Soda S., Development of 400kN Magnetorheological Damper for a Real Base-Isolated Building, In: Proceedings of SPIE-International Society for Optics Engineering: Smart Structures and materials 2003: Damping and Isolation, San Diego, CA, 2-6 March, 265-276.

Genc S., Synthesis and Properties of Magnetorheological (MR) Fluids, PhD Dissertation, University of Pittsburgh, 2002.

Goncalves F.D., Characterizing the Behavior of Magne-Torheological Fluids at High Velocities and High Shear Rates, PhD Thesis, Virginia Polytechnic, Blacksburg, 2005. 
Hahm D., Ok S.-Y., Park W., Koh H.-M., Park K.-S., Cost-Effectiveness Evaluation of an MR Damper System Based on a Life-Cycle Cost Concept, KSCE Journal of Civil Engineering, 17, 145-154 (2013).

Hajalilou A., Mazlan S.A., Lavvafi H., Shameli K., Magnetorheological Fluid Applications, In: Hajalilou A., Mazlan S.A., Lavvafi H. et al. (Eds.) Field Responsive Fluids as Smart Materials, Singapore, Springer, 2016, 67-81.

Hiemenz G.J., Hu W., Wereley N.M., Semi-Active Magnetorheological Helicopter Crew Seat Suspension for Vibration Isolation, Journal of Aircraft, 45, 945-953 (2008).

Jim Toscano J.K., Improving Operator Comfort, 2009a, Available at: http://articles.sae.org/6727/.

Jim Toscano J.K., SAE Off-Highway Engineering, 2009b, Available at: http://articles.sae.org/6727/.

Jolly M.R., Properties and Applications of Magnetorheological Fluids, Vol. 604 (Symposium LL - Materials for SmartSystems III) 167 (1999), DOI: https://doi.org/10.1557/PROC-604-167.

Jolly M.R., Bender J.W., Carlson J.D., Properties and Applications of Commercial Magnetorheological Fluids, In: 5th Annual International Symposium on Smart Structures and Materials, San Diego, CA, 1998, 1-5 March, 262-275.

Kim H.-C., Shin Y.-J., You W., Jung K.C., Oh J.-S., Choi S.-B., A Ride Quality Evaluation of a Semi-Active Railway Vehicle Suspension System with MR Damper: Railway Field Tests, Proceedings of the Institution of Mechanical Engineers, Part F: Journal of Rail and Rapid Transit, 231, 306-316 (2016).

Kormann Cl., Laun M., Klett G., Actuator, 4th International Conference on New Actuators, H. Borgmannn and K. Lenz (Eds.), Germany: Axon Technologie Consult GmbH, 1994, 271.

Melle S., Fuller G.G., Rubio M.A., Structure and Dynamics of Magnetorheological Fluids in Rotating Magnetic Fields, Physical Review E., 2000, 61, 4111.

Naserimojarad M.M., Moallem M., Arzanpour S., Smart Fluid Damper, CA2984533 (A1) - 2019-05-01.

Olabi A.-G., Grunwald A., Design and Application of Magneto-Rheological Fluid, Materials \& Design, 28, 2658-2664 (2007).

Rabinow J., AIEE Trans., National Bureau of Standards Technical News Bulletin, 1948.

Raju A., Seung-Bok C., MdMeftahul F., A State of Art on Magneto-Rheological Materials and their Potential Applications, Journal of Intelligent material Systems and structures, 1-45 (2018), DOI: 10.1177/1045389X18754350.

Shtarkman E. M., Fluid Responsive to a Magnetic Field, US Patent 4, 992, 190-1991.

Shtarkman E.M., Fluid Responsive to a Magnetic Field, US Patent 5, 167, 850-1992.

Shutto S., Toscano J.R. Magnetorheological (MR) Fluid and its Applications, In: Proceedings of the JFPS International Symposium on Fluid Power, TSUKUBA, 7-10 November 2005, 590-594, The Japan Fluid Power System Society.

Skalski P., Kalita K., Role of Magnetorheological Fluids and Elastomers in Today's World, Actamechanica et Automatica, 2017, 11, 4, 267-274.

Spaggiari A., Properties and Applications of Magnetorheological Fluids, Frattura Ed. Integrità Strutturale, 2013, 23, 57-61.

Stănescu C., Luca P.I., Boiangiu V., Florescu D., Balliu S., Florea F., Lubricant Composition, RO116558 (B1) - 2001-03-30. 
Sun S.S., Ning D.H., Yang J., Du H., Zhang S.W., Li W.H., A Seat Suspension with a Rotary Magnetorheological Damper for Heavy Duty Vehicles, Smart Materials and Structures, 25, 105032 (2016).

Tang X., Zhang X., Tao R., Rong Y., Structure-Enhanced Yield Stress of Magnetorheological Fluids, Journal of Applied Physics, 87, 2634-2638 (2000).

Tian Li, Zhou Mengyao, Chen Cheng, Gao Guodong, Rotation Type Self-Adaption Magnetorheological Fluid Damper, CN 108869614(A)-2018-11-23.

Tian T., Li W., Alici G., Du H.., Deng Y.M., Microstructure and Magnetorheology of Graphite-Based MR Elastomers, Rheologica Acta, 50, 825-836 (2011).

Truong D.Q., Ahn K.K., MR Fluid Damper and Its Application to Force Sensorless Damping Control System. Smart Actuation and Sensing Systems - Recent Advances and Future Challenges, Ed. InTechOpen, 2012, Chapter 15, 383-424 http://dx.doi.org/10.5772/51391.

Vidican I., Mureşan R., Bejan M., Considerații despre amortizoarele magnetoreologice la vehiculele feroviare, A XIII-a Conferinţă Naţională multidisciplinară-cu participare internaţională, „Profesorul Dorin Pavel-fondatorul hidroenergeticii româneşti", Sebeş, 2013.

Wang D., Wang B., Zi B., Qian S., Wang Z., Qian J., Chen B., Luo Y., Automobile Brake Pedal Feeling Simulator Based on Magnetorheological Damper. CN109278728 (A) - 2019-01-21.

Wang D., Zi B., Zeng Y., Qian S., Simulation and Experiment on Transient Temperature Field of a Magnetorheological Clutch for Vehicle Application, Smart Materials and Structures, 26, 095020 (2017).

Wang J., Meng G., Magnetorheological Fluid Devices: Principles, Characteristics and Applications in Mechanical Engineering, Proceedings of the Institution of Mechanical Engineers, Part L: Journal of Materials Design and Applications, 215, 165-174 (2001).

Winslow W.M., Induced Fibration of Suspensions, J. Appl. Phys., 20, 1137-1140 (1949).

Yabin L., Weifeng M., Qi L., Shijun L., Yanwei C., Shuguo P., Yang H., Magnetorheological Damper and Magnetorheological Fluid Perfusion Method. CN108980260 (A) - 2018-12-11.

Yang S.-Y., Do X.P., Choi S.-B., Design of magnetorheological mount for a cabin of heavy equipment vehicles, In: SPIE-International Society for Optics Engineering: Smart Structures and Materials + Non Destructive Evaluation and Health Monitoring, Las Vegas, NV, 2016, 20-24 March, 9799, 97992S.

Yu M., Dong X., Choi S.B., Liao C.R., Human Simulated Intelligent Control of Vehicle Suspension System with MR Dampers, Journal of Sound and Vibration, 319, 753-767, (2009).

Zapateiro M., Karimi H.R., Luo N., Spencer B.F., Frequency Domain Control Based on Quantitative Feedback Theory for Vibration Suppression in Structures Equipped with Magnetorheological Dampers, Smart Materials and Structures, 18, 095041 (2009).

** Lord Corporation (n.d.-a), Industrial V. 2003 Available at: http://www.lord.http://www.lord.com/products-and-solutions/active-vibrationcontrol/industrial-suspensionsystems.

https://patents.google.com/

https://ro.espacenet.com/ 


\section{ASPECTE PRIVIND UTILIZAREA FLUIDELOR MAGNETOREOLOGICE ÎN CONSTRUCŢIA AMORTIZOARELOR}

\section{(Rezumat)}

În lucrarea de faţă se face o trecere în revistă a cunoştințelor despre fluidele magnetoreologice ce fac parte din clasa materialelor inteligente. Acestea sunt fluide care nu respectă legea lui Newton, energizarea lor realizându-se prin intermediul unui câmp magnetic exterior. În esenţă, lichidul magnetoreologic este o soluţie sintetică pe bază de hidrocarbonaţi, populată cu particule din material magnetic moale (uşor de magnetizat şi demagnetizat). Amortizoarele care utilizează fluide magnetice, sunt întâlnite în industria automobilelor, pentru preluarea vibrațiilor. Amortizorul cu element elastic şi fluid magnetoreologic prezintă următoarele avantaje: posibilitatea de control electric a cursei și a vitezei de răspuns a sistemului piston-cilindru, printr-o metodă fără contact; are o construcţie simplă şi fiabilă; amortizorul propus este o construcție etanşă; nu sunt necesare elemente de etanşare interne compatibile cu fluidul magnetoreologic; amortizorul nu prezintă componente cu mișcare relativă la nivelul elementului de comandă, reducând forțele de frecare. 